\title{
The Outcome of Patients with Melanoma Is Not Associated with the Time Point of Lymphatic Mapping with Respect to Excisional Biopsy of the Primary Tumor
}

\author{
Katharina J. Gauwerky ${ }^{a}$ Christian Kunte ${ }^{a} \quad$ Till Geimer $^{\mathrm{a}} \quad$ Jens Baumert ${ }^{\mathrm{a}}$ b \\ Michael J. Flaig ${ }^{a}$ Thomas Ruzicka ${ }^{a}$ Monika-Hildegard Schmid-Wendtner ${ }^{a}$ c \\ Carola Berking ${ }^{a}$ \\ ${ }^{a}$ Department of Dermatology and Allergology, Ludwig Maximilian University of Munich, and ${ }^{\mathrm{b}}$ Institute of \\ Epidemiology, Helmholtz-Zentrum München, German Research Center for Environmental Health, Munich; \\ 'Department of Dermatology and Allergology, University of Bonn, Bonn, Germany
}

\section{Key Words}

Melanoma, excisional biopsy · Sentinel lymph node biopsy

\begin{abstract}
Background: Sentinel lymph node biopsy (SLNB) has become the standard care for melanoma and is an important diagnostic procedure. It has been doubted whether lymphoscintigraphy detects the correct sentinel lymph node (SLN) when excision of the tumor and SLNB are not performed at the same time. This would imply that this sequential approach may have an increased risk of undetected micrometastases resulting in a worse outcome. Objective: The purpose of the present study was to compare the outcome of melanoma patients having received excision of the tumor and SLNB either at the same time or consecutively. Methods: A total of 854 patients with cutaneous melanoma were enrolled in this retrospective study between September 1996 and November 2007. Disease-free (DFS) and overall survivals (OS) were estimated using the Kaplan-Meier product limit method and were analyzed by the log rank test. Results: No statistically significant difference was found regarding DFS,
\end{abstract}

progression rates and OS in patients with primary tumor excision and SLNB at the same time compared with patients with excisional biopsy of primary tumor and SLNB at different times. Conclusion: These data suggest that excisional biopsy of the primary tumor does not prevent the correct SLN mapping in melanoma patients.

Copyright $\odot 2010$ S. Karger AG, Basel

\section{Introduction}

The incidence of melanoma has increased significantly in the last few decades. Surgery is the gold standard in the treatment of primary melanoma, while the histological tumor thickness according to Breslow is decisive for safety margins and the indication for sentinel lymph node biopsy (SLNB). At present, SLNB is recommended at a tumor thickness greater than $1 \mathrm{~mm}[1,2]$. The sentinel lymph node (SLN) is the first regional lymph node on

K.J.G., C.K., M.H.S.W. and C.B. contributed equally to this work.

\section{KARGER}

Fax +41613061234 E-Mail karger@karger.ch www.karger.com
Christian Kunte, MD, Department of Dermatology and Allergology

Ludwig Maximilian University of Munich

Frauenlobstrasse 9-11, DE-80337 Munich (Germany)

Tel. +49895160 6600, Fax +498951606646

E-Mail Christian.Kunte@med.uni-muenchen.de 
the direct lymphatic pathway from the primary melanoma. If tumor cells have metastasized, they are most likely located in the SLN. SLNB was initially described by Morton et al. [3] and is recognized as an important diagnostic procedure with a great prognostic value, while a therapeutic benefit has not been shown yet.

In most skin cancer centers in Europe, SLNB is performed according to European melanoma guidelines with two common approaches $[1,4,5]$ : (i) excisional biopsy of the primary tumor with histological confirmation of tumor type and thickness followed by a wide excision (1 cm and more) and SLNB, or (ii) wide excision of the primary tumor and SLNB at the same time, provided that the clinical diagnosis is obvious, possibly supported by dermoscopy and by high-frequency ultrasound for the preoperative evaluation of tumor thickness [6-8].

It is still controversially discussed how far the surgical procedure of the excisional biopsy of the primary tumor alters the lymphatics leading to different draining SLNs. It has been questioned whether lymphatic mapping shows consistent results with or without prior excisional biopsy of the primary melanoma. It was hypothesized that a nonidentical lymphatic mapping would lead to an increased probability of false-negative SLNB and thus higher rates of progressive disease, especially of regional lymph node metastases.

\section{Patients and Methods}

At our dermatology unit, 1,049 consecutive patients had been identified for SLNB between September 1996 and November 2007. Most of them presented with cutaneous melanomas with a Breslow thickness $>1 \mathrm{~mm}$ or with other risk factors such as ulceration or regression of primary melanoma as well as Clark level IV and V. No SLN could be detected in 29 out of 1,049 patients (2.76\%) for technical reasons. Thus, the detection rate was $97.24 \%$. In 166 patients, missing information concerning tumor type, tumor thickness, Clark level or follow-up data led to the exclusion from the study. Therefore, a total of 854 patients could be enrolled in this study.

In patients with clinical suspicion of melanoma, the diagnosis was corroborated using dermoscopy. A measurement of tumor thickness was performed preoperatively using $20-\mathrm{MHz}$ high-frequency ultrasound (DUB 30, Taberna pro medicum, Lüneburg, Germany) [6-8].

Postoperatively, the median tumor thickness was $2.15 \mathrm{~mm}$ as determined histologically. If excisional biopsy of the primary melanoma had been performed elsewhere, the original slides were re-examined by an experienced dermatopathologist (M.F.) at our department. The primary tumor was excised within 4 weeks prior to SLNB $(n=549)$ or at the same time as SLNB $(n=305)$. A safety margin of $1 \mathrm{~cm}$ was chosen for primary tumors up to $2 \mathrm{~mm}$ in thickness, while thicker tumors were excised with a safety mar- gin of $2 \mathrm{~cm}$ according to the German melanoma guidelines. In most patients with both surgical procedures at different time points, excisional biopsy of the primary tumor was performed at first followed by a wide excision ( $1 \mathrm{~cm}$ or more) together with SLNB.

In only 4 patients had primary tumor excision already been performed with a safety margin of $1 \mathrm{~cm}$.

\section{SLNB Procedure}

Two to $16 \mathrm{~h}$ prior to SLNB, dynamic lymphoscintigraphy was performed using technetium-99m-labeled human serum albumin colloid (Solco-Nanokoll, Sorin-Biomedica, Munich, Germany) in collaboration with the Department of Nuclear Medicine, University of Munich. The skin site corresponding to the hottest emission point was marked. On the day of surgery, a hand-held gamma camera (C-Trak System, Care Wise, Morgan Hill, Calif., USA) was used to measure background and SLN radioactivity pre- and intraoperatively. In addition, intradermal injection of 0.5-1.0 ml of patent blue V (Guerbet, Sulzbach, Germany) was performed $10-15 \mathrm{~min}$ preoperatively about $0.5 \mathrm{~cm}$ around the primary tumor or excision scar. The SLN was identified as a hot and blue-stained lymph node. SLNB was performed using standard procedures. All lymph nodes exhibiting radioactive impulse rates of at least $10 \%$ of the lymph node with the maximal radioactive impulse rate were surgically removed [9].

\section{Histopathological Evaluation}

For histopathological examination, the SLN was bisected along the long axis after formalin fixation. From each paraffin block, 8-12 sections were prepared for staining with hematoxylin and eosin and Giemsa as well as for immunohistochemical analysis (S100, HMB45, NKiC3, Melan A). The tumor load was documented for each SLN concerning location within the lymph node and size (micrometastasis and macrometastasis). Lymph nodes with histologically proven deposits of more than 3 tumor cells were considered metastatic. Primary tumors and the specimens from complete lymphadenectomies were examined using routine histology [9].

\section{Surgical and Adjuvant Therapies}

Patients with metastases in the SLN (213/854 patients; positive SLN) were recommended to undergo a radical lymph node dissection of the regional basin [9]. Of these, 176 patients $(83 \%)$ underwent this procedure. The lymph nodes of the neck were removed by a modified neck dissection, the axillary nodes by a level II dissection and the inguinal nodes by an ilioinguinal dissection (cranially up to the iliac bifurcation and caudally to the apex of the femoral triangle). All patients with primary melanoma $\geq 1.5 \mathrm{~mm}$ thickness as well as patients with positive SLN were considered for low-dose $\alpha$-interferon therapy $(3 \times 3$ million IU s.c. per week). The adjuvant treatment courses were not recorded in detail for this study, but they were performed according to study protocols of the German Dermatologic Cooperative Oncology Group [10]. The duration of adjuvant treatment varied between 18 and 60 months.

\section{Statistical Analysis}

The association of patient and tumor characteristics with time point of lymphatic mapping ( 1 vs. 2) was assessed by the $\chi^{2}$ test. Disease-free (DFS) and overall survival (OS) curves were estimat- 
ed using the Kaplan-Meier product limit method and were analyzed for significant differences by the log rank test. The significance level was determined at $\mathrm{p}<0.05$. To assess the risk of different surgical procedures on DFS and OS with respect to the impact of different tumor- and patient-related factors, we calculated 3 models using Cox regression analysis with different adjustments. The analyses were performed with the statistical software package SPSS, version 16.0 (Chicago, Ill., USA).

\section{Follow-Up}

The follow-up of all patients was conducted by clinical examination and ultrasound of regional lymph nodes at our dermatology unit in intervals according to the German follow-up guidelines. Tumor progression as well as survival was documented, additionally.

\section{Results}

The distributions of patient and tumor characteristics for all patients stratified by time point of lymphatic mapping are shown in table 1 . The median age of all patients was 55 years (range $9-83$ years); 485 were male $(56.8 \%)$ and 369 female (43.2\%). Almost half of the patients (49.7\%) were between 51 and 70 years of age. The median tumor thickness was $1.6 \mathrm{~mm}$ (range $0.2-19 \mathrm{~mm}$ ). The time point of lymphatic mapping was significantly associated with all patient and tumor characteristics except for the Clark level.

To determine if the sequence of surgical procedures (excisional biopsy of the primary melanoma and subsequent SLNB at different time points vs. wide excision of the primary melanoma and SLNB at the same time) had a significant effect on the course of the disease, survival analysis (Kaplan-Meier estimator with log rank tests for bivariate comparisons) was performed.

\section{Description of Outcome Analysis}

A total of 1,491 SLNs were excised in 854 patients (mean 1.75 per patient). A total of 549 patients underwent excisional biopsy of the primary melanoma and SLNB at different time points (group 1), while 305 patients received both surgical interventions at the same time (group 2). In group 1, 88 (16\%) of 594 patients developed progression of disease compared to 59 (19.3\%) of 305 patients in group 2 (table 2 ). There was no significant difference with respect to the mode of progression, i.e. metastasis in the regional lymphatic basin, either: in group 1 , progression in regional lymph nodes was found in 20 patients $(3.6 \%)$ compared to 15 patients $(4.91 \%)$ in group $2(\mathrm{p}=0.34$; table 2$)$.

Melanoma Outcome and Lymphatic Mapping
Table 1. Clinical and pathological characteristics of the study population $(\mathrm{n}=854)$

\begin{tabular}{|c|c|c|c|c|}
\hline & $\begin{array}{l}\text { Complete } \\
\text { study } \\
\text { population }\end{array}$ & $\begin{array}{l}\text { Tumor excision } \\
\text { and SLNB at the } \\
\text { same time }\end{array}$ & $\begin{array}{l}\text { Tumor excision } \\
\text { and SLNB } \\
\text { consecutively }\end{array}$ & $\begin{array}{l}\mathrm{p} \\
\text { value }\end{array}$ \\
\hline \multicolumn{5}{|l|}{ Sex } \\
\hline Male & $485(56.8)$ & $192(63)$ & $293(53.4)$ & 0.007 \\
\hline Female & $369(43.2)$ & $113(37)$ & $256(46.6)$ & \\
\hline \multicolumn{5}{|l|}{ Age, years } \\
\hline Mean & 55 & 55.33 & 51.66 & \\
\hline Minimum & 9 & 18 & 9 & \\
\hline Maximum & 83 & 83 & 80 & \\
\hline \multicolumn{5}{|l|}{ Age groups } \\
\hline$\leq 40$ & $177(20.7)$ & $39(12.8)$ & $138(25.1)$ & \\
\hline $41-50$ & $174(20.4)$ & $67(22)$ & $107(19.5)$ & \\
\hline $51-60$ & $214(25.1)$ & $81(26.6)$ & $133(24.2)$ & \\
\hline $61-70$ & $210(24.6)$ & $83(27.2)$ & $127(23.1)$ & \\
\hline$>70$ & $79(9.3)$ & $35(11.5)$ & $44(8)$ & \\
\hline \multicolumn{5}{|c|}{ Localization of primary tumor } \\
\hline Head & $48(5.6)$ & $19(6.2)$ & $29(5.3)$ & $<0.001$ \\
\hline Body & $376(44.0)$ & $145(47.5)$ & $223(42.1)$ & \\
\hline Upper extremity & $112(13.1)$ & $27(8.9)$ & $85(15.5)$ & \\
\hline Lower extremity & $245(28.7)$ & $72(23.6)$ & $173(31.5)$ & \\
\hline Acral & $73(8.5)$ & $42(13.8)$ & $31(5.6)$ & \\
\hline \multicolumn{5}{|c|}{ Tumor thickness, $\mathrm{mm}$} \\
\hline Mean & 1.6 & 2,103 & 2,178 & $<0.001$ \\
\hline Minimum & 0.2 & 0.2 & 0.45 & \\
\hline Maximum & 19 & 14 & 19 & \\
\hline \multicolumn{5}{|l|}{ Thickness classes } \\
\hline$\leq 0.75 \mathrm{~mm}$ & $53(6.2)$ & $40(13.1)$ & $13(2.4)$ & \\
\hline $0.76-1.00$ & $94(11.0)$ & $38(12.5)$ & $56(10.2)$ & \\
\hline $1.01-1.50$ & $262(30.7)$ & $63(20.7)$ & $199(36.2)$ & \\
\hline $1.51-2.00$ & $159(18.6)$ & $63(20.7)$ & $96(17.5)$ & \\
\hline $2.01-4.00$ & $211(24.7)$ & $70(23)$ & $141(25.7)$ & \\
\hline$>4.00$ & $75(8.8)$ & $31(10.2)$ & $44(8)$ & \\
\hline \multicolumn{5}{|l|}{ Clark level } \\
\hline II & $19(2.2)$ & $11(3.6)$ & $8(1.5)$ & 0.230 \\
\hline III & $309(36.2)$ & $107(35.1)$ & $202(36.8)$ & \\
\hline IV & $493(57.7)$ & $176(57.7)$ & $317(57.7)$ & \\
\hline $\mathrm{V}$ & $33(3.9)$ & $11(3.6)$ & $22(4)$ & \\
\hline \multicolumn{5}{|l|}{ Histological subtype } \\
\hline $\mathrm{NM}$ & $318(37.2)$ & $95(31.1)$ & $223(40.6)$ & $<0.001$ \\
\hline SSM & $283(33.1)$ & $113(37)$ & $170(31)$ & \\
\hline SNSSM & $133(15.6)$ & $55(18)$ & $78(14.2)$ & \\
\hline Spitzoid melanoma & $34(4.0)$ & $1(0.3)$ & $33(6)$ & \\
\hline ALM & $46(5.4)$ & $34(11.1)$ & $12(2.2)$ & \\
\hline Other & $40(4.7)$ & $7(2.3)$ & $33(6)$ & \\
\hline \multicolumn{5}{|c|}{ Further characteristics } \\
\hline Not specified & $302(35.4)$ & $103(33.8)$ & $199(36.2)$ & $<0.001$ \\
\hline Nodular & $161(18.9)$ & $45(14.8)$ & $116(21.1)$ & \\
\hline Secondary nodular & $110(12.9)$ & $43(14.1)$ & $67(12.2)$ & \\
\hline Nevus associated & $96(11.2)$ & $26(8.5)$ & $70(12.8)$ & \\
\hline Ulceration & $81(9.5)$ & $25(8.2)$ & $56(10.2)$ & \\
\hline Regression & $42(4.9)$ & $30(9.8)$ & $12(2.2)$ & \\
\hline Other & $62(7.3)$ & $33(10.8)$ & $29(5.3)$ & \\
\hline
\end{tabular}

$\mathrm{NM}=$ Nodular melanoma; SSM = superficial spreading melanoma; SNSSM = secondary nodular superficial spreading melanoma; $\mathrm{ALM}=$ acral lentiginous melanoma. Figures in parentheses are percentages. 


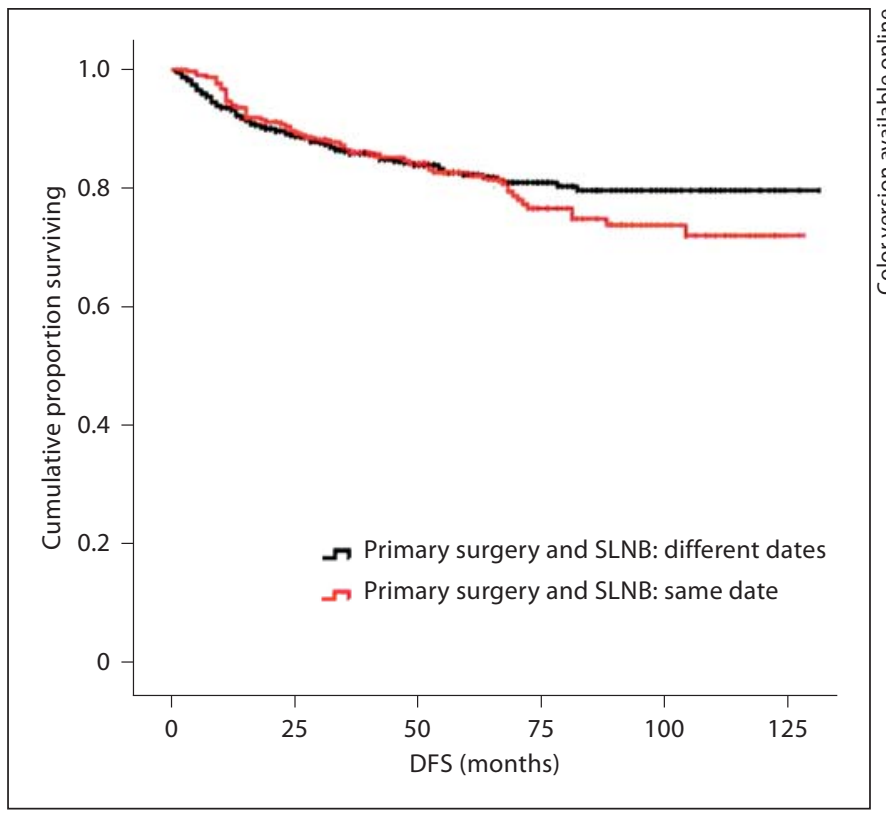

Fig. 1. DFS of patients with positive SLNs estimated by the Kaplan-Meier method.

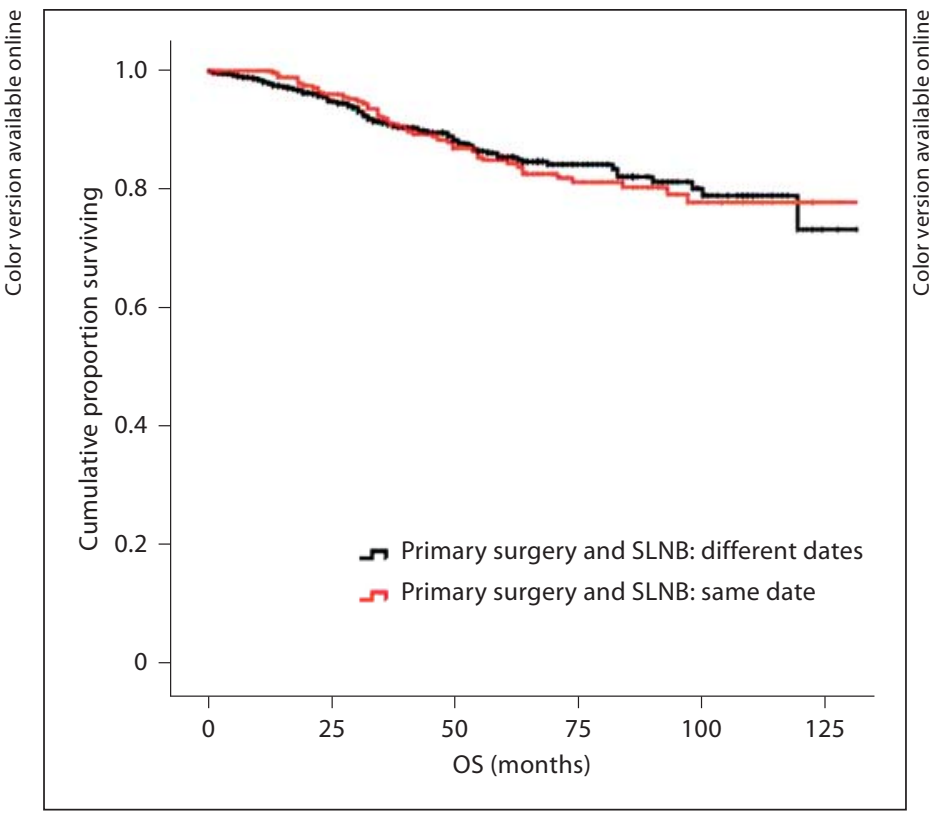

Fig. 2. OS of patients with negative SLNs estimated by the KaplanMeier method.

Table 2. Association between sequence of surgical procedure and kind of progression

\begin{tabular}{|c|c|c|c|c|c|}
\hline & \multirow{2}{*}{$\begin{array}{l}\text { No } \\
\text { progression }\end{array}$} & \multicolumn{3}{|l|}{ Progression } & \multirow[t]{2}{*}{ Total } \\
\hline & & lymph node relapse & other & sum & \\
\hline Tumor excision and SLNB at the same time & $246(80.7 \%)$ & $15(4.91 \%)$ & $44(14.42 \%)$ & $59(19.3 \%)$ & $305(100 \%)$ \\
\hline Tumor excision and SLNB consecutively & $461(84 \%)$ & $20(3.6 \%)$ & $68(12.4 \%)$ & $88(16 \%)$ & $549(100 \%)$ \\
\hline Total & $707(82.8 \%)$ & $35(4.3 \%)$ & $112(13.3 \%)$ & $147(17.2 \%)$ & $854(100 \%)$ \\
\hline
\end{tabular}

Table 3. Survival analysis using the Kaplan-Meier estimator

\begin{tabular}{lll}
\hline Tumor excision and SLNB & $\begin{array}{ll}\text { DFS (log rank test: } \\
\mathrm{p}=0.472), \text { months }\end{array}$ & $\begin{array}{l}\text { OS (log rank test: } \\
\mathrm{p}=0.844) \text {, months }\end{array}$ \\
\hline At the same time & 110.02 & 113.39 \\
Consecutively & 104.54 & 113.2 \\
\hline Total & 108.56 & 113.41 \\
\hline
\end{tabular}

\section{Results of Survival Analysis}

Patients who had undergone both surgical interventions at different time points (group 1) showed a DFS of 110.2 months, while patients with excision of the primary tumor and SLNB at the same time (group 2) had a DFS of
104.54 months $(\mathrm{p}=0.472)$. The OS in group 1 was 113.39 months compared to 113.2 months in group $2(\mathrm{p}=0.844)$. As these differences between both groups were not statistically significant, the sequence of surgical procedures did not seem to affect the risk of tumor progression (table 3).

A subdivision of the two groups with respect to the presence of SLN metastasis showed no significant difference in DFS: patients with positive SLNs in group 1 had a median DFS of 82.11 months compared to 77.65 months in group 2 (fig. $1 ; \mathrm{p}=0.805$ ). Patients with negative SLNs in group 1 had a median DFS of 118.7 months compared to 113.96 months in group 2 (fig. $2 ; \mathrm{p}=0.805$ ).

The time point of lymphatic mapping was not significantly associated with DFS or OS as shown by calculating 3 models using Cox regression analysis with different ad- 
Table 4. Multivariate analysis - survival and complete lymph node dissection by Cox regression

\begin{tabular}{|c|c|c|c|c|c|c|}
\hline & \multicolumn{3}{|l|}{ DFS } & \multicolumn{3}{|l|}{ OS } \\
\hline & $\mathrm{HR}$ & $95 \% \mathrm{CI}$ & $\mathrm{p}$ & HR & $95 \% \mathrm{CI}$ & $\mathrm{p}$ \\
\hline Model I & 0.886 & $0.637-1.233$ & 0.473 & 0.963 & $0.662-1.401$ & 0.844 \\
\hline Model II & 0.952 & $0.683-1.327$ & 0.771 & 1.092 & $0.749-1.591$ & 0.648 \\
\hline Model III & 1.027 & $0.733-1.438$ & 0.877 & 1.129 & $0.772-1.650$ & 0.532 \\
\hline
\end{tabular}

$\mathrm{HR}=$ Hazard ratio; $\mathrm{CI}=$ confidence interval. Surgical modality was excision of the tumor and SLNB either at the same time or consecutively. Model I included the variable surgical modality. Model II included variables surgical modality, age and sex. Model III included variables surgical modality, age, sex, histological tumor type characteristics (nodular + secondary nodular + nevus, ulceration, regression, not specified + other), tumor thickness, histological tumor type (nodular melanoma, superficial spreading melanoma + secondary nodular superficial spreading melanoma, acral lentiginous melanoma, other + spitzoid) and localization of primary.

justments, notwithstanding the fact that all patient and tumor characteristics except for the Clark level were different in both groups. Hazard ratios in the model adjusted for basic risk factors such as age, tumor thickness and histological subtype were 1.027 for DFS and 1.129 for OS ( $p$ values 0.877 and 0.532 ) and similar to the hazard ratios without adjustment (table 4).

The reliability of the lymph node mapping could also be demonstrated by 2 individual cases: in 2 patients, lymphoscintigraphy had been performed twice, i.e. before and after excisional biopsy of the primary melanoma, because the originally planned excision of the SLN had to be canceled due to the unintentional oral intake of metformin. Therefore, a few days later a second lymphoscintigraphy was performed followed by SLNB and a wide excision with the recommended safety margins. In both cases, it seemed that the identical SLNs were mapped in the same regional lymphatic basins. Figures 3 and 4 show the lymph node mapping before and after excision of the primary melanoma of the respective patients.

\section{Discussion}

SLNB has become the gold standard in the surgical management of cutaneous melanoma with a Breslow thickness $>1 \mathrm{~mm}[2,11-13]$. In selected cases (young patient age, ulceration of the primary melanoma, Clark level IV or V, signs of regression), SLNB is also recommended in patients with melanomas thinner than $1 \mathrm{~mm}$. The detection of micrometastasis in the SLN is the most important negative prognostic factor $[14,15]$. In case of SLN metastasis, regional lymph node dissection is commonly

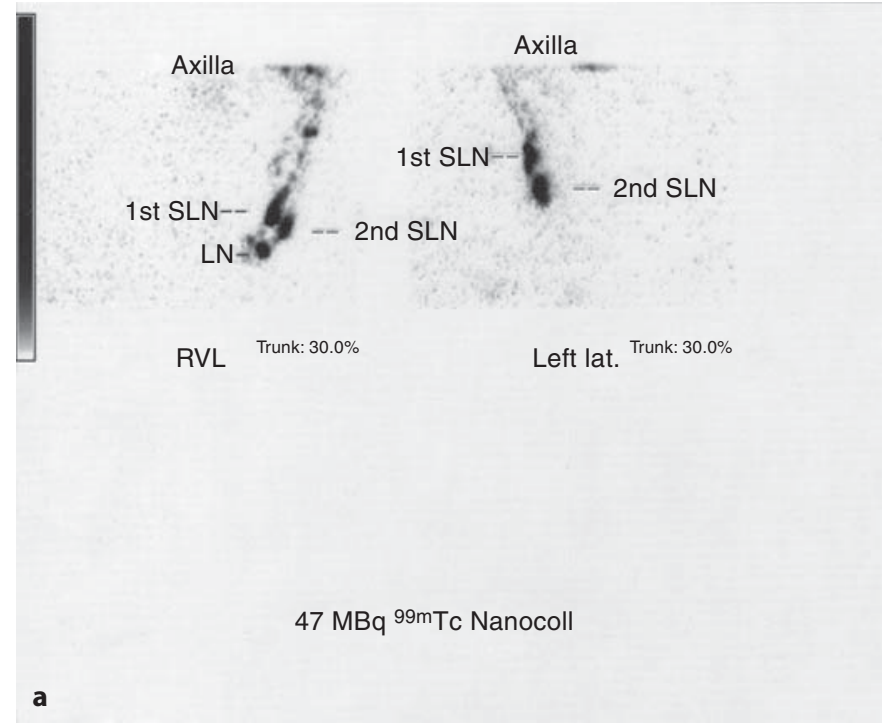

Axilla
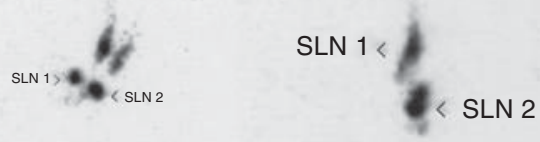

b

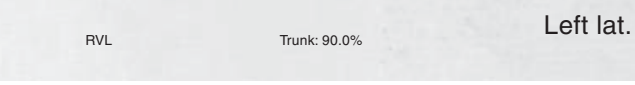

Fig. 3. Patient 1 , lymphoscintigraphy before (a) and after excision (b) of the primary tumor. RVL = Right/ventral/left.

Dermatology 2010;220:355-362 

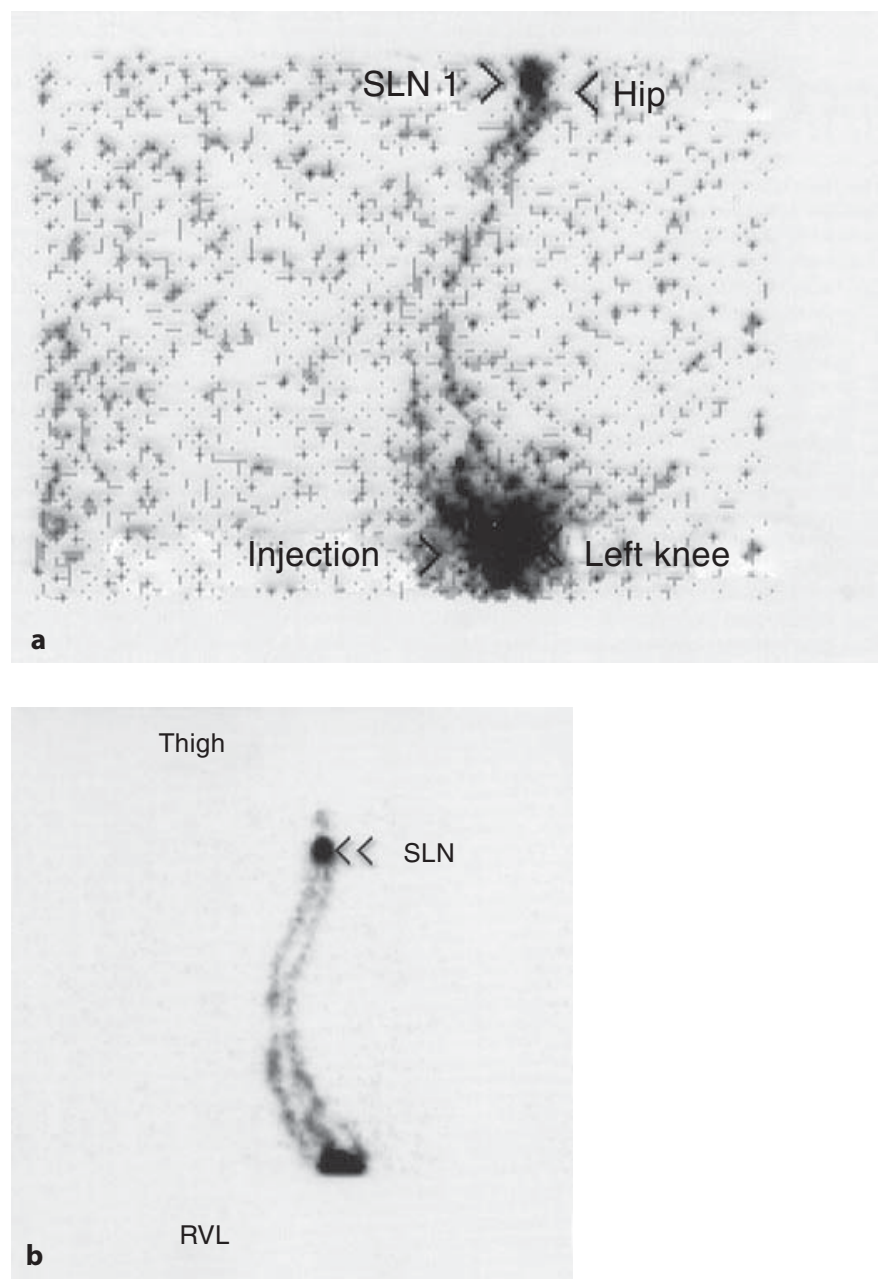

Fig. 4. Patient 2 , lymphoscintigraphy before (a) and after excision (b) of the primary tumor. RVL = Right/ventral/left.

recommended. While SLNB is accepted as an important diagnostic procedure, the opinions about a possible therapeutic effect are very controversial, and data from large prospective clinical trials are still missing $[10,16,17]$.

Since SLNB is a standardized and well-established procedure in most skin cancer centers, its reproducibility is of the utmost importance [18]. Previous studies have indicated that lymphoscintigraphy for lymphatic mapping in melanoma is reproducible $[19,20]$.

Whether the time point of primary tumor excision and SLNB, i.e. at the same time or at a different time, affects the accuracy of the lymph node mapping and consequently the further course of disease is still under discussion. Frequently, primary tumor excision and SLNB are not carried out at the same time point. However, there are concerns that the patterns of afferent lymphatic flow from a primary tumor site may be altered as a result of disruption of the lymphatic vessels. This disruption may negatively impact on the identification of the SLN or the correct pathological status of the draining lymph node basins in these patients, since the actually identified drainage pathways may no longer represent the original ones of the primary tumor $[20,21]$. Consequently, SLNB could miss the true SLNs and identify false-negative SLNs. In these patients, the possible benefit of a complete lymph node dissection and of an adjuvant therapy at an early stage would not even be considered [22].

These problems do not exist when the primary tumor excision and SLNB are performed at the same time. However, in many cases excisional biopsy of the primary tumor is performed initially because the clinical diagnosis needs to be confirmed first and the tumor thickness of melanoma is uncertain $[23,24]$. Very commonly the primary excision takes place in a nonspecialized outpatient setting before the patients are then referred to the hospital for SLNB. Our present data show that $64.2 \%$ of the patients underwent excisional biopsy of the primary melanoma and SLNB at different time points. Hence, a complete understanding of the accuracy and validity of SLNB after excisional biopsy of the primary tumor is mandatory. The results of a univariate analysis show no significant correlation between the sequence of surgical procedures and general disease progression $(\mathrm{p}=0.219)$, or with progression in regional lymph nodes either $(\mathrm{p}=0.304)$. In fact, the number of relapses in regional lymph nodes was even lower in patients who had received excisional biopsy of the primary tumor and SLNB at different time points (3.6\%) compared to patients who had both surgical procedures at the same time (4.91\%). These data indicate that excisional biopsy of the primary tumor does not significantly alter lymphatic vessels leading to different lymphatic drainage.

Moreover, the sequence of surgical procedures does not seem to influence DFS and OS: there was no statistically significant difference in both groups regarding DFS $(\mathrm{p}=0.472)$ and $\mathrm{OS}(\mathrm{p}=0.844)$. After differentiation of both groups into SLN-positive and SLN-negative patients, no differences concerning DFS and OS could be observed either.

All patient and tumor characteristics except for the Clark level were different in both groups (primary tumor excision and SLNB performed at the same time or consecutively). A possible selection bias could be excluded by calculating 3 models using Cox regression analysis with different adjustments. 
The results of our study suggest that SLN mapping remains accurate, even though excisional biopsy of the primary tumor and SLNB are performed at different time points, because this approach did not show higher rates of false-negative SLNs or worse survival rates. These results are supported by a previously published prospective study in which Trifiro et al. [25] could demonstrate that in 23 of 31 cases lymphoscintigraphy before and after excisional biopsy was concordant in terms of nodal basins visualized. False-negative results were obtained in 8 patients: in 2 patients, the second lymphoscintigraphy did not identify any lymph node basin, while an additional basin appeared in 6 patients. Other studies indicated that even after wide local excision ( $1 \mathrm{~cm}$ or more) including primary closure as well as split-thickness skin graft lymphatic mapping and SLNB were accurate [22, 26-28].

Regional relapses (false-negative SLN) were only seen in patients who underwent rotation flap grafting prior to SLNB, so this procedure is considered to be a contraindication. In some cases, patients may show an increased number of SLNs and drainage to additional lymph node regions [29].

In summary, regional lymph node mapping and SLNB subsequent to excisional biopsy of the primary tumor are accurate and have no other impact on OS and DFS compared to both surgical procedures performed at the same time.

\section{References}

1 Dummer R, Hauschild A, Pentheroudakis G: Cutaneous malignant melanoma: ESMO clinical recommendations for diagnosis, treatment and follow-up. Ann Oncol 2009; 20(suppl 4):129-131.

2 Garbe C, Eigentler TK: Diagnosis and treatment of cutaneous melanoma: state of the art 2006. Melanoma Res 2007;17:117-127.

3 Morton DL, Wen DR, Wong JH, Economou JS, Cagle LA, Storm FK, Foshag LJ, Cochran AJ: Technical details of intraoperative lymphatic mapping for early stage melanoma. Arch Surg 1992;127:392-399.

4 Garbe C, Schadendorf D, Stolz W, Volkenandt M, Reinhold U, Kortmann RD, Kettelhack C, Frerich B, Keilholz U, Dummer R, Sebastian G, Tilgen W, Schuler G, Mackensen A, Kaufmann R, Hauschild A: Short German guidelines: malignant melanoma. J Dtsch Dermatol Ges 2008;6(suppl 1):S9-S14.

5 Roberts DL, Anstey AV, Barlow RJ, Cox NH, Newton Bishop JA, Corrie PG, Evans J, Gore ME, Hall PN, Kirkham N: UK guidelines for the management of cutaneous melanoma. $\mathrm{Br}$ J Dermatol 2002;146:7-17

6 Homolak D, Vucetic B, Puljiz Z, Blajc I, Vurnek Zivkovic M, Situm M: Our experience of melanoma thickness as a predictor of outcome of sentinel node biopsy. Coll Antropol 2008;32(suppl 2):57-60.

7 Serrone L, Solivetti FM, Thorel MF, Eibenschutz L, Donati P, Catricala C: High frequency ultrasound in the preoperative staging of primary melanoma: a statistical analysis. Melanoma Res 2002;12:287-290.

8 Wong SL, Brady MS, Busam KJ, Coit DG: Results of sentinel lymph node biopsy in patients with thin melanoma. Ann Surg Oncol 2006;13:302-309.
9 Cochran AJ, Balda BR, Starz H, Bachter D, Krag DN, Cruse CW, Pijpers R, Morton DL: The Augsburg Consensus: techniques of lymphatic mapping, sentinel lymphadenectomy, and completion lymphadenectomy in cutaneous malignancies. Cancer 2000;89: 236-241.

10 Ollila DW, Ashburn JH, Amos KD, Yeh JJ, Frank JS, Deal AM, Long P, Thomas ND, Meyers MO: Metastatic melanoma cells in the sentinel node cannot be ignored. J Am Coll Surg 2009;208:924-929, discussion 929-930.

11 Balch CM, Buzaid AC, Atkins MB, Cascinelli N, Coit DG, Fleming ID, Houghton A Jr, Kirkwood JM, Mihm MF, Morton DL, Reintgen D, Ross MI, Sober A, Soong SJ, Thompson JA, Thompson JF, Gershenwald JE, McMasters KM: A new American Joint Committee on Cancer staging system for $\mathrm{cu}-$ taneous melanoma. Cancer 2000;88:14841491.

12 Balch CM, Morton DL, Gershenwald JE, McMasters KM, Nieweg OE, Powell B, Ross MI, Sondak VK, Thompson JF: Sentinel node biopsy and standard of care for melanoma. J Am Acad Dermatol 2009;60:872875.

13 Ross MI: New American Joint Commission on Cancer staging system for melanoma: prognostic impact and future directions. Surg Oncol Clin North Am 2006;15:341352.

14 Balch CM, Soong SJ, Gershenwald JE, Thompson JF, Reintgen DS, Cascinelli N, Urist M, McMasters KM, Ross MI, Kirkwood JM, Atkins MB, Thompson JA, Coit DG, Byrd D, Desmond R, Zhang Y, Liu PY, Lyman GH, Morabito A: Prognostic factors analysis of 17,600 melanoma patients: validation of the American Joint Committee on Cancer melanoma staging system. J Clin Oncol 2001; 19:3622-3634.
15 Gershenwald JE, Thompson W, Mansfield PF, Lee JE, Colome MI, Tseng CH, Lee JJ, Balch CM, Reintgen DS, Ross MI: Multi-institutional melanoma lymphatic mapping experience: the prognostic value of sentinel lymph node status in 612 stage I or II melanoma patients. J Clin Oncol 1999;17:976983.

16 Carlson GW, Murray DR, Lyles RH, Staley CA, Hestley A, Cohen C: The amount of metastatic melanoma in a sentinel lymph node: does it have prognostic significance? Ann Surg Oncol 2003;10:575-581.

17 Van der Ploeg IM, Kroon BB, Antonini N, Valdes Olmos RA, Nieweg OE: Is completion lymph node dissection needed in case of minimal melanoma metastasis in the sentinel node? Ann Surg 2009;249:1003-1007.

18 Thompson JF, Uren RF: Lymphatic mapping in management of patients with primary cutaneous melanoma. Lancet Oncol 2005;6: 877-885.

19 Kapteijn BA, Nieweg OE, Valdes Olmos RA, Liem IH, Panday RK, Hoefnagel CA, Kroon BB: Reproducibility of lymphoscintigraphy for lymphatic mapping in cutaneous melanoma. J Nucl Med 1996;37:972-975.

20 Uren RF, Howman-Giles R, Chung DK, Morton RL, Thompson JF: The reproducibility in routine clinical practice of sentinel lymph node identification by pre-operative lymphoscintigraphy in patients with cutaneous melanoma. Ann Surg Oncol 2007;14: 899-905.

21 Uren RF, Howman-Giles RB, Shaw HM, Thompson JF, McCarthy WH: Lymphoscintigraphy in high-risk melanoma of the trunk: predicting draining node groups, defining lymphatic channels and locating the sentinel node. J Nucl Med 1993;34:1435-1440. 
22 Ariyan S, Ali-Salaam P, Cheng DW, Truini C: Reliability of lymphatic mapping after wide local excision of cutaneous melanoma. Ann Surg Oncol 2007;14:2377-2383.

23 Rossi CR, Pasquali S, Mocellin S: Actual false-negative rate prompts the routine use of ultrasound scan before and after sentinel node biopsy in melanoma. Ann Surg Oncol 2008;15:2976-2977.

24 Schmid-Wendtner MH, Dill-Muller D: Ultrasound technology in dermatology. Semin Cutan Med Surg 2008;27:44-51.
25 Trifiro G, Verrecchia F, Soteldo J, Zonta M, Pizzigoni S, Travaini LL, Baldini F, Tosti G, Mosconi M, Paganelli G, Mazzarol G, Testori A: Modification of lymphoscintigraphic sentinel node identification before and after excisional biopsy of primary cutaneous melanoma. Melanoma Res 2008; 18:373-377.

26 Karakousis CP, Grigoropoulos P: Sentinel node biopsy before and after wide excision of the primary melanoma. Ann Surg Oncol 1999;6:785-789.

27 Leong WL, Ghazarian DM, McCready DR Previous wide local excision of primary melanoma is not a contraindication for sentine lymph node biopsy of the trunk and extremity. J Surg Oncol 2003;82:143-146.
28 McCready DR, Ghazarian DM, Hershkop MS, Walker JA, Ambus U, Quirt IC: Sentinel lymph-node biopsy after previous wide local excision for melanoma. Can J Surg 2001;44: 432-434.

29 da Silva N Jr, Anselmi CE, Riccardi F, Furian R, Fernandes DD, Brito R, de Lima M, Anselmi OE: The surgical management of the sentinel lymph node in cutaneous melanoma might be different when the primary lesion was previously resected with $1 \mathrm{~cm}$ margin. Nucl Med Commun 2009;30:565-568. 